\title{
SEASONAL VARIATION OF NITROGEN CYCLING IN MANILA BAY
}

\author{
Mitsuru Hayashi ${ }^{1}$, Tetsuo Yanagi ${ }^{2}$ and Maria Lourdes San Diego-Mcglone ${ }^{3}$ \\ 15-1-1, Fukaeminami, Kobe 658-0022 Japan, Kobe University \\ ${ }^{2} 6-1$ Kasuga park, Kauga, Fukuoka, 816-8580, Japan, Kyushu University \\ ${ }^{3}$ Diliman, Quezon City, 1101, Philippines, University of the Philippines
}

\begin{abstract}
Seasonal variation in nitrogen cycling at the upper layer of the Pasig River estuary in Manila Bay was calculated during January 1996 to December 1998 by using the numerical ecosystem model. Chl.a and DIN concentrations are relatively low, river discharge is small, and solar radiation is strong from March to May in dry season. The main reason of low chl.a concentration is that the solar radiation is too strong. On the other hand, as DIN concentration is relatively high and solar radiation is optimum, chl. a concentration is relatively high from August to December in rainy season. Main source of DIN in rainy season is the vertical transport from the lower layer due to the strong estuarine circulation.
\end{abstract}

Keywords: Manila Bay, Numerical ecosystem model, Nitrogen cycling, Seasonal variation

\section{INTRODUCTION}

Recently, water quality of Manila Bay has been deteriorating and red tides frequently occur. Related to such condition in Manila Bay, Jacinto et al. (1998) calculated $\mathrm{N}$ and $\mathrm{P}$ budgets of Manila Bay using LOICZS biogeochemical budgeting procedure. Bajarias and Relox (1996) discussed the distribution of toxic Pyrodinium. Azanza R.V et al. (2004) analyzed the correlations between the cyst density of red tide organism and benthic fluxes of nitrogen and phosphorus. Hayashi et al. (2006) calculated the nitrogen cycling in Manila Bay during dry and rainy seasons. Nitrogen is the limiting nutrient of primary production in Manila Bay (Hayashi et al., 2006). Nitrogen is used slowly and many times due to small nitrogen supply and weak estuarine circulation in dry season. But nitrogen is sufficiently supplied and is used quickly in primary production in rainy season. Moreover nitrogen is also quickly flushed out by strong estuarine circulation in rainy season.

However, the generation mechanism of red tides in Manila Bay has not been clarified yet. We have to reveal the characteristics of the nitrogen cycling in Manila Bay, in order to clarify the generation mechanism of red tide. In this paper we described the seasonal variation of nitrogen cycling in Manila Bay using the numerical ecosystem model, and the main factor which affects the primary production is clarified.

\section{MATERIALS AND METHODS}

\section{Study Area}

Fig. 1 shows the study area of Manila Bay. It has two major rivers, Pasig River and Pampang River. Pasig River flows through Metro Manila. Vertical distribution of water temperature, salinity, chl. a concentration, Dissolved Inorganic Nitrogen (DIN) concentration were observed at the $1 \mathrm{~m}$ depth, the middle and the bottom layers at eight stations in every month during March 1996 to December 1998. Fig. 2 shows the depth-time diagrams of $\sigma$ (a), chl.a concentration (b) and DIN concentration (c) at each observation station. Figures are arranged to correspond to the locations of observation site. When river discharge is large as shown in Fig.3, the mixed layer depth is $3 \mathrm{~m}$. We can find high chla concentration in the upper layer especially in the Pasig River estuary. The high chl.a concentration (over $5 \mu \mathrm{g} l^{-1}$ ) occurred once or twice in the year. But it was not periodic. DIN concentration is higher in the inner part of the bay, and DIN at the lower layer in the outer 


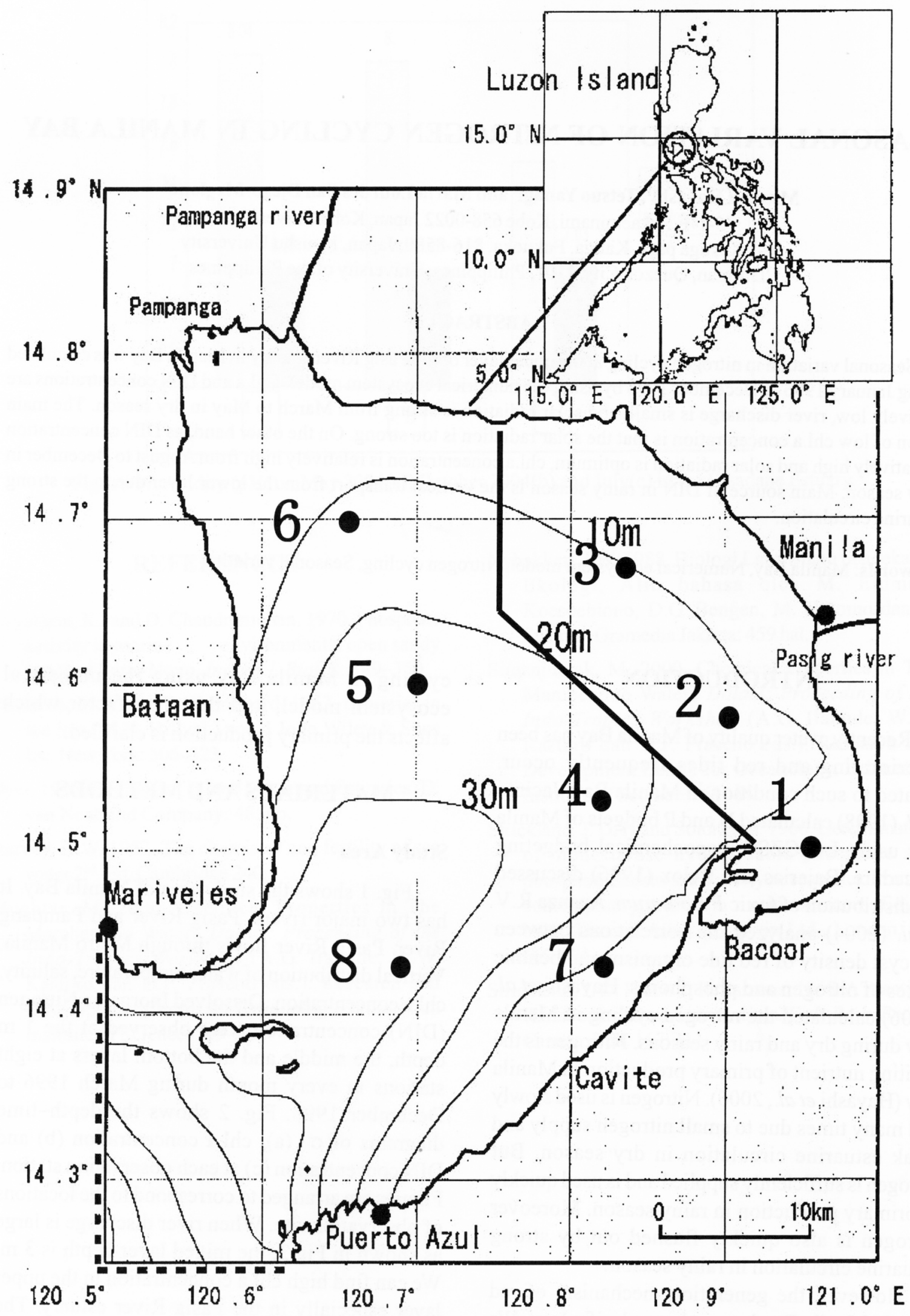

Figure 1. Study area and the observation stations in Manila Bay. The line shows the boundary between the box and the outer area. 


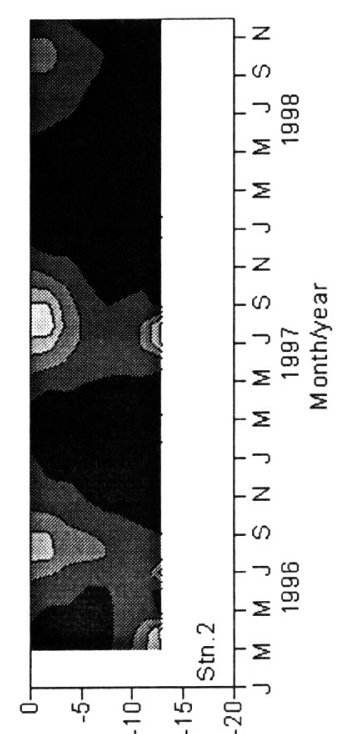

(w) uldəo

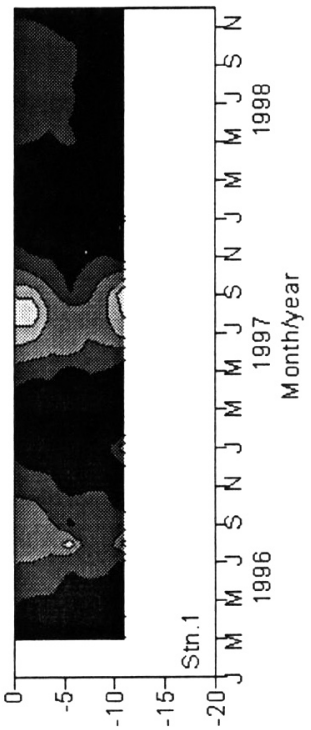

(w) पldə0

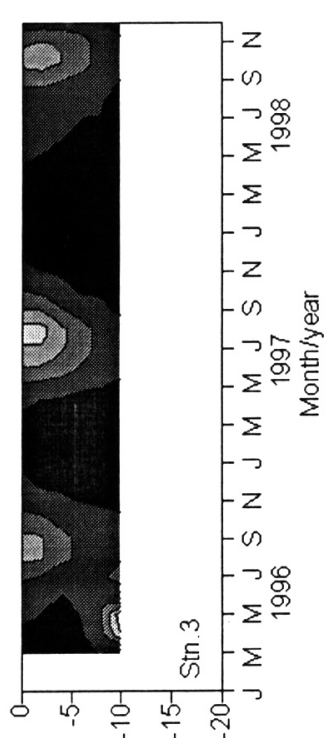

(w) uाder

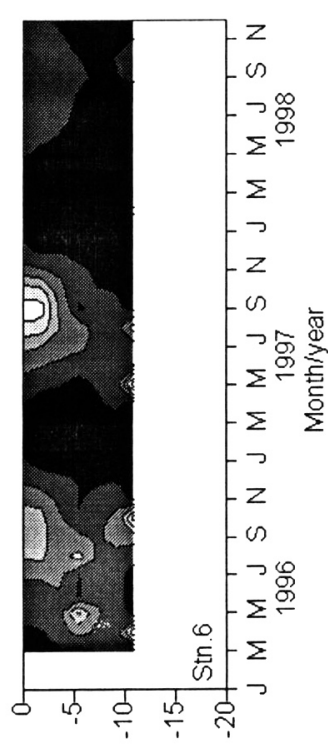

(w) प1də0

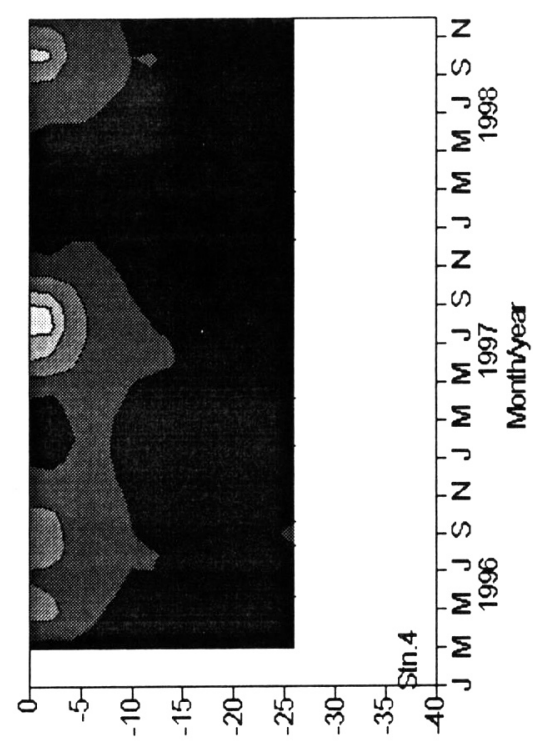

(ui) updad

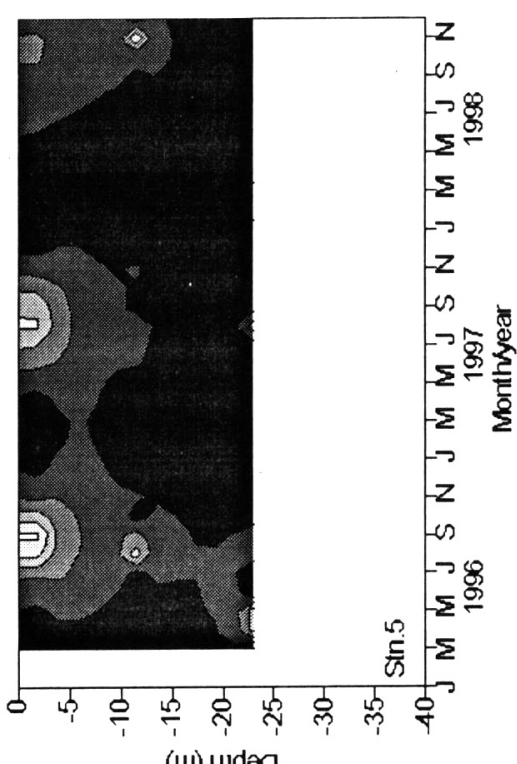

(ui) uाdळa

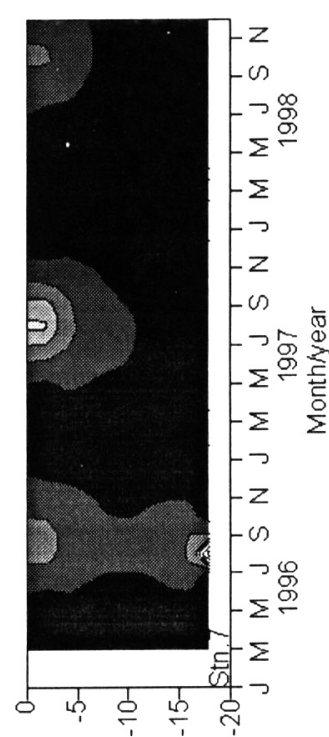

(w) 47da0

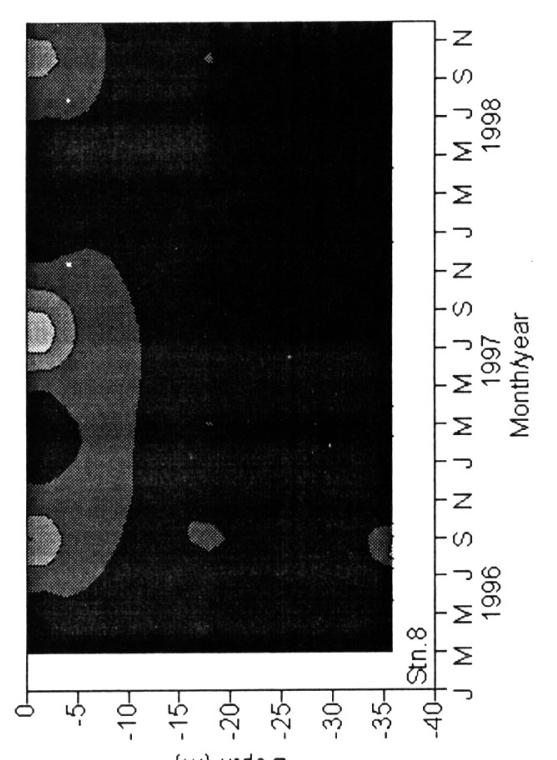

(w) 41də0 


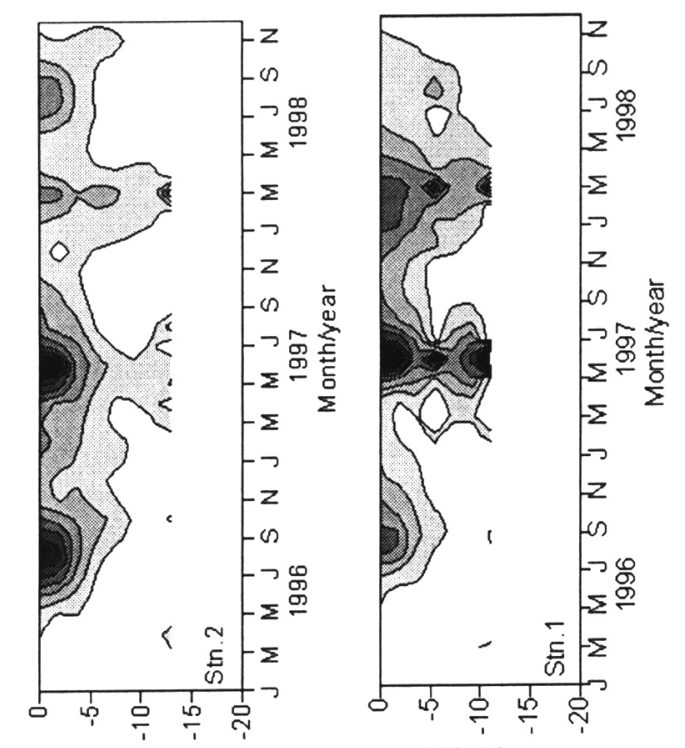

(w) 47dəo

(w) प1deO

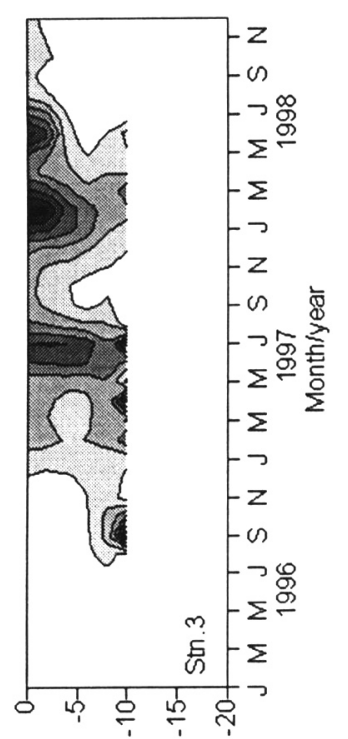

(w) प1de्

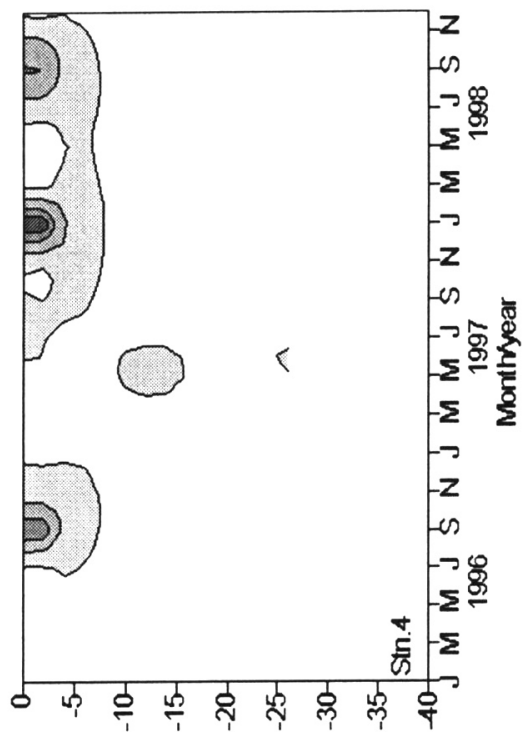

(ui) प1de0

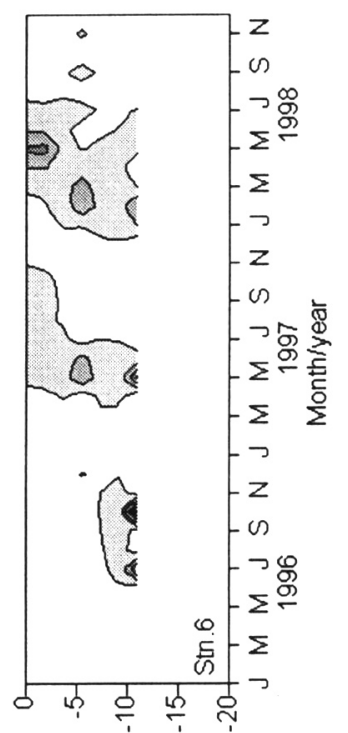

(w) प1deO

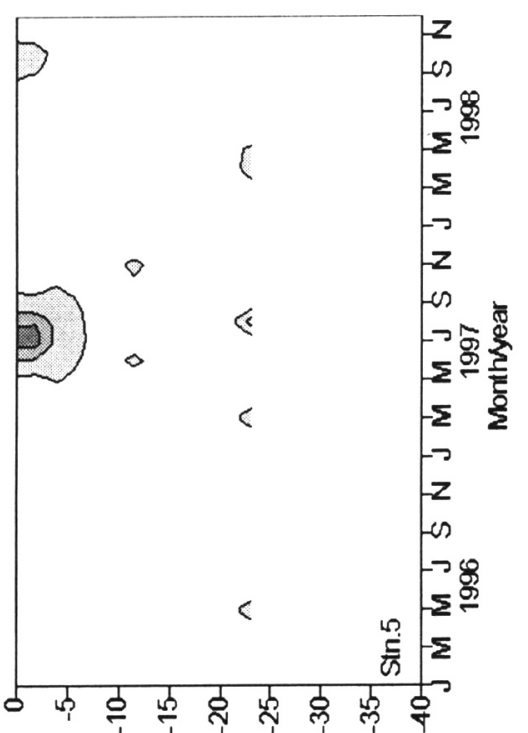

(u) पıdøa

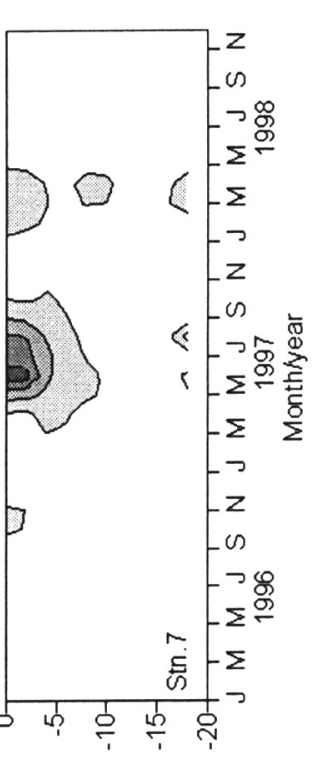

(w) uldag 


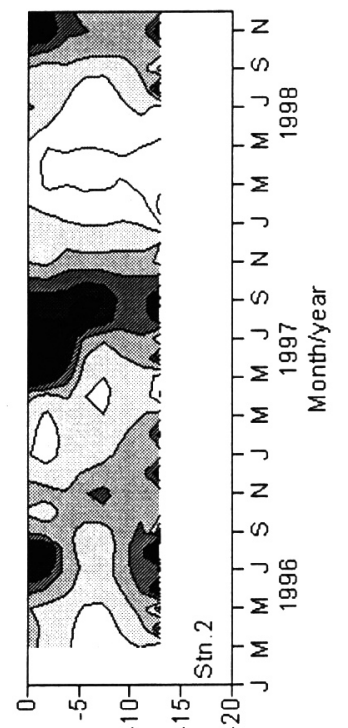

(u) $47 \mathrm{~d} ә$

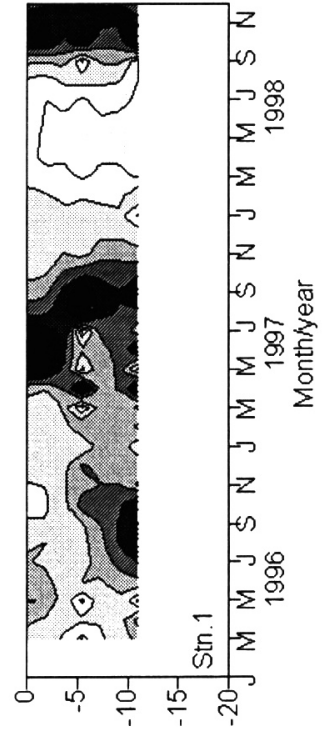

(w) प1daO

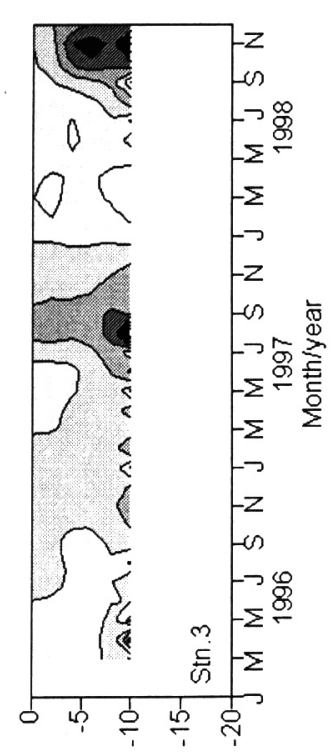

(w) पld

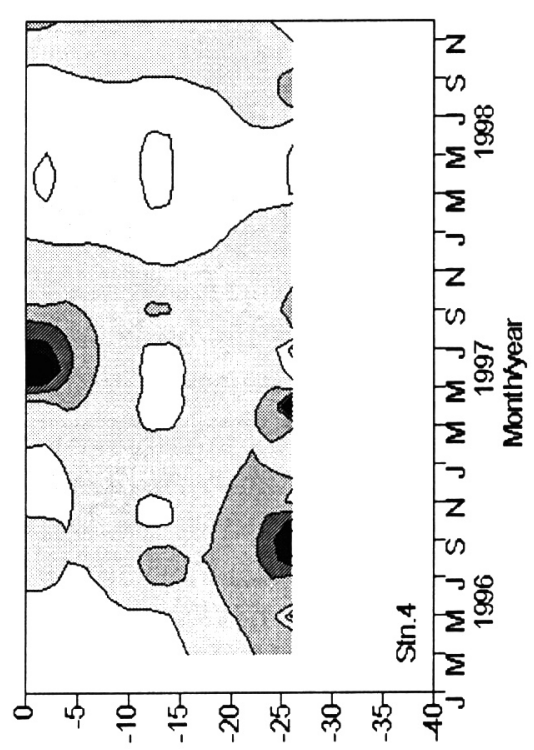

(ui) पाdə0

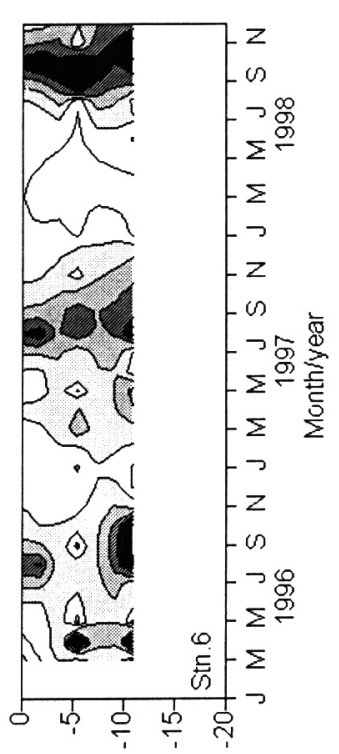

(u) $47 \mathrm{~d} \partial 0$

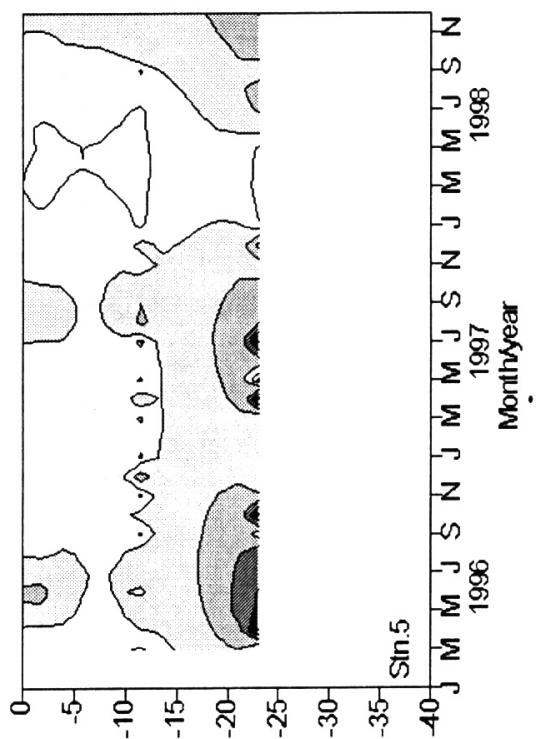

(u) पıd

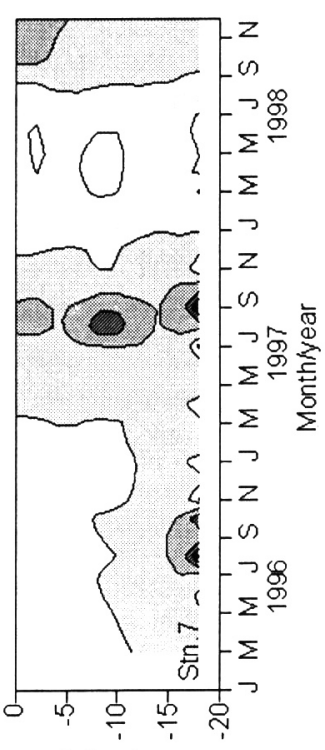

(w) प1d 


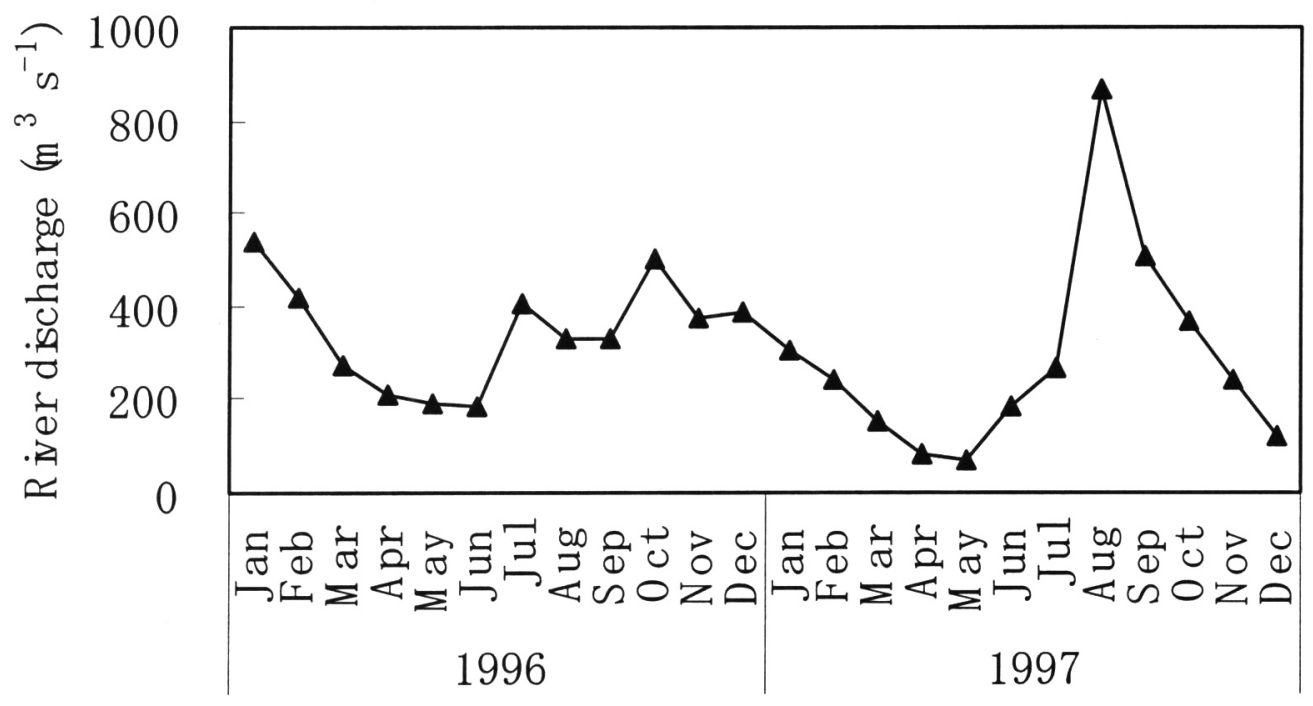

Figure 3. The temporal variations of the Pasig and Pampanga River discharge.

part of the bay is higher than that at the upper layer, but it is lower than those in the inner part.

\section{Numerical Ecosystem Model}

In this study, the monthly nitrogen cycling at the upper layer in the Pasig River estuary with 10 $m$ water depth shown in Figurel is calculated by using the numerical ecosystem model. Calculation period is from January 1996 to December 1998. The upper layer is the calculated box with $3 \mathrm{~m}$ depth, $35 \mathrm{~km}$ boundary line and $500 \mathrm{~km}^{2}$ surface area as shown in Figure 4. Length between the box and outer area is $16 \mathrm{~km}$.

The numerical ecosystem model has five compartments, DIN, phytoplankton (PHY), zooplankton (ZOO), detritus (DET) and DON (Dissolved Organic Nitrogen), as shown in Figure 4. Nitrogen cycling in the box is mainly based on the bio-chemical processes. The model also includes nitrogen load from the land, sinking process of phytoplankton and detritus, and advection and diffusion of nitrogen related to the estuarine circulation.

Temporal change of concentration of each compartment in the box is expressed by the equations. For example, Equation 1 shows the temporal change of DIN concentration. It consists of three parts, biochemical process, boundary condition and physical process.

where $A_{1}, B_{2}, C_{1}$ and $D_{1}$ are the coefficients of biochemical processes, $V_{u}$ is the volume of box, $F_{u}$ is the surface area of the box, $F_{s}$ is the boundary area, $L$ is the horizontal length between the box and the adjacent area, $H$ is the vertical length between the upper and lower layers, $U$ is the horizontal advection speed, $W$ is the vertical advection speed, $K_{h}$ is the horizontal eddy diffusivity, $K_{v}$ is the vertical eddy diffusivity. Subscript $u$ refers to the upper layer, subscript $l$ refers to the lower layer, and subscript $o$ refers to the outer part.

Biochemical processes are represented by other equations. $A_{l}$ represents photosynthesis speed and is the functions of DIN concentration, water temperature $(T)$ and photon in the water $(I)$, as shown by Equation 2 .

where $V_{\max }$ denotes the maximum specific nitrogen uptake rate, $K_{n}$ is the half saturation constant, $k_{t}$ is the coefficient of temperature dependency, $T_{o p t}$ is the optimum water temperature, $I_{o p t}$ is the optimum photon. Other equations of the temporal change of concentration

$$
\begin{aligned}
& \frac{d D I N_{u}}{d t}=-A_{1} P H Y_{u}+B_{2} Z O O_{u}+C_{1} D E T_{u}+D_{1} D O N_{u} \\
&+\frac{1}{V}\left(D I N_{\text {land }}-F_{u} U D I N_{u}+F_{s} W D I N_{l}+F_{u} \frac{K_{h}}{L}\left(D I N_{o}-D I N_{u}\right)+F_{s} \frac{K_{v}}{H}\left(D I N_{l}-D I N_{u}\right)\right), \\
& A_{1}=V_{\max } \times \frac{D I N}{D I N+K_{n}} \times\left(\frac{\exp \left(k_{t} T\right)}{\exp \left(k_{t} T_{\text {opt }}\right)}\right)^{2} \times \frac{I}{I_{\text {opt }}} \exp \left(1-\frac{I}{I_{\text {opt }}}\right),
\end{aligned}
$$




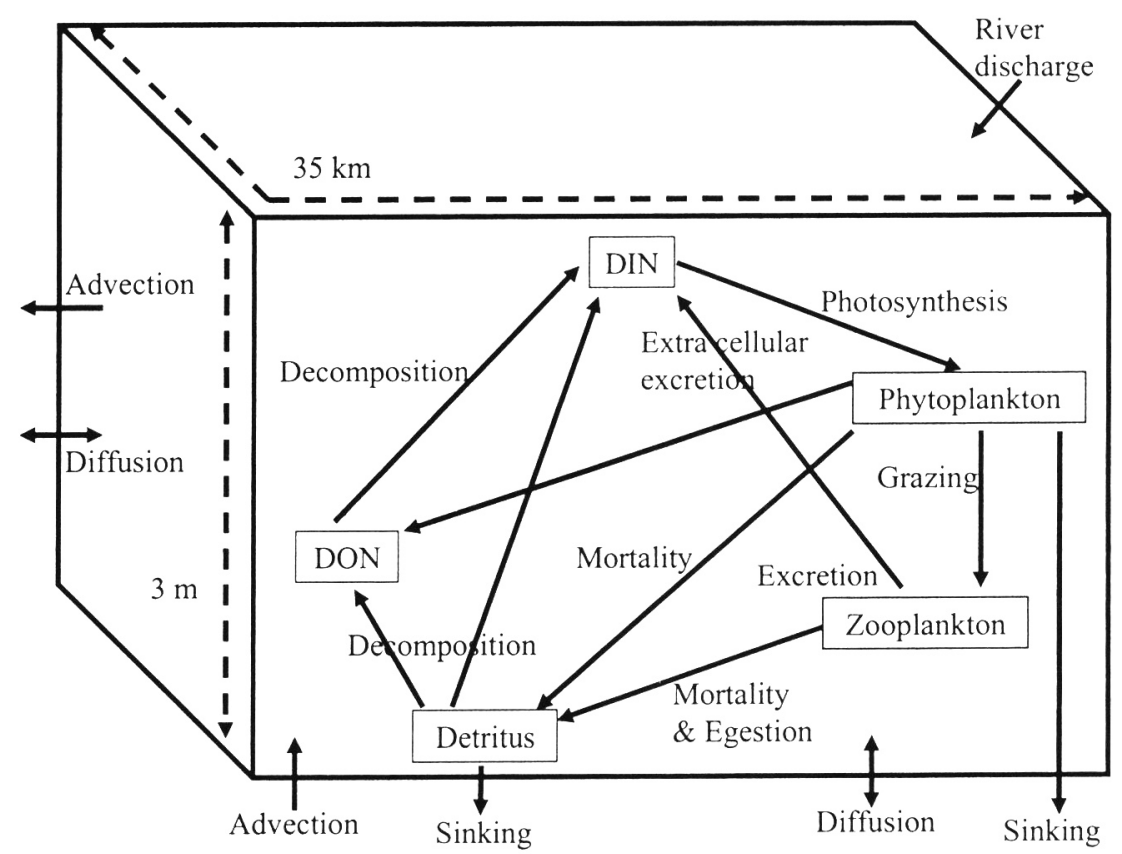

Figure 4. The numerical ecosystem model.

and the biochemical processes are referred to Hayashi and Yanagi (2002).

\section{Data}

Physical parameters, $K_{h}, K_{v}$ and $U$ are referred to Fujiie et al. (2002) which calculated the 3dimentional residual current distributions in April (dry season) and November (rainy season). From their results, $K_{h}$ is constant as $10^{5} \mathrm{~cm}^{2} \mathrm{~s}^{-1} . K_{v}$ is averaged vertical diffusivity at the boundary section between the upper and lower layers. $U$ is averaged residual current speed along the boundary section between the box and the outer area. Seasonal variations of $K_{v}$ and $U$ are given by the seasonal variation of the averaged Pasig River discharge $(Q)$ (Jacinto et al., 1998). Stratification in the Pasig River estuary is mainly dominated by river discharge (Fujiie et al, 2002). Therefore $K_{v}$ is proportional to Q but $U$ is antiproportional to $\mathrm{Q}$. Vertical velocity across the lower boundary of box $W$ in every month is estimated by the water budget in the box, $W-U+Q+D=0 . D$ is the difference between precipitation and evaporation.

Figure 5 shows the estimated seasonal variations of $K_{v}$ (a), $U$ and $W($ b). In dry season, stratification is week due to small river discharge ( $K_{v}$ is large), and the estuarine circulation ( $U$ and $W)$ is weak. In rainy season, stratification is strong due to large river discharge ( $K_{v}$ is small), and the estuarine circulation is strong.

Seasonal variations of physical parameters, photon in the water and water temperature are shown in Figure 6 (a) and (b). Average photon in the water from the surface to three $m$ depth is estimated by solar radiation and transparency in every month. Water temperature in the box is average of the field observation data in the upper layers of stations 1, 2 and 3.

Boundary condition in the outer area of the box is the average of field observation data in the surface layer of stations 4, 5 and 6. Boundary condition in the lower layer of the box is the average of field observation data at the middle and lower layers of stations 1, 2 and 3. Figure 7 shows the seasonal variation of DIN (a) and chl.a (b) concentrations in the outer area. Figure 8 shows those in the lower layer. Total nitrogen (TN) concentration was estimated by the ratio of TN concentration to DIN concentration which was observed in Osaka Bay (Hashimoto et al., 1996). DIN load from rivers and coastal zone to Manila Bay is $900 \times 10^{6}$ moles $\mathrm{y}^{-1}$ and $600 \times 10^{6}$ moles $\mathrm{y}^{-1}$, respectively (Jacinto et al., 1998). DIN load from Pasig River in every month in 1996 and 1997 was given as proportional to river discharge shown in Fig.9 (a). We do not have the Pasig River discharge data in 1998. So DIN load from Pasig River in every month in 1998 was given by the average of 1996 and 1997. Direct DIN load from the coastal 
zone to Manila Bay is added to DIN load from Pasig River. Figure 9 (b) shows the estimated DIN load from land. Moreover TN load from land is estimated by the ratio of TN load to DIN load which was observed in Hakata Bay (Yanagi and Onitsuka, 2000). The sinking speeds of

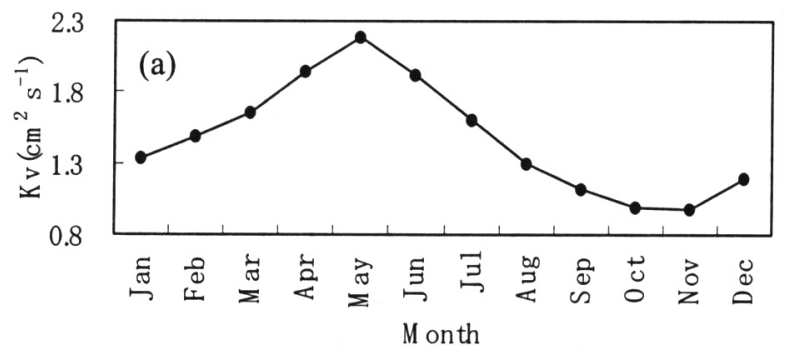

phytoplankton and detritus are estimated by the annual average of TN budget in the box. It is assumed that they are constant and the sinking speed of phytoplankton is $10 \%$ of that of detritus, and they are $6.7 \times 10^{-6} \mathrm{~cm} \mathrm{~s}^{-1}$ and $6.7 \times 10^{-5} \mathrm{~cm} \mathrm{~s}^{-1}$, respectively.

(b)

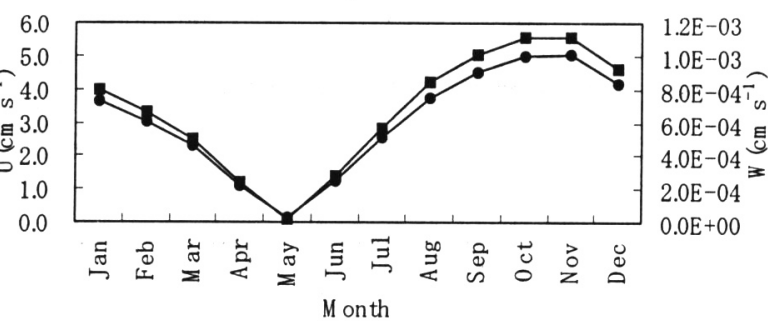

Figure 5. The estimated seasonal variations of $K v(\mathrm{a})$ and $U$ and $W(\mathrm{~b})$.

(a)

$$
\rightarrow 1996 \rightarrow-1997 \multimap 1998
$$

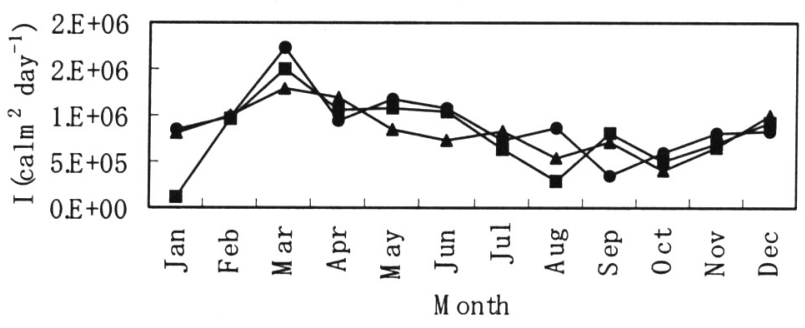

(b)

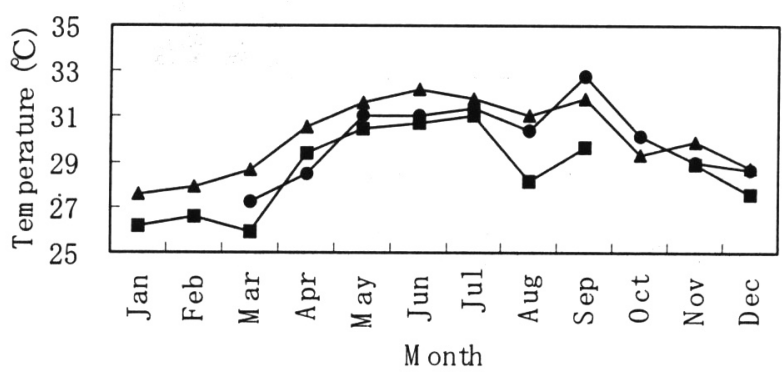

Figure 6. The seasonal variations of photon in the water (a) and water temperature (b).

(a)

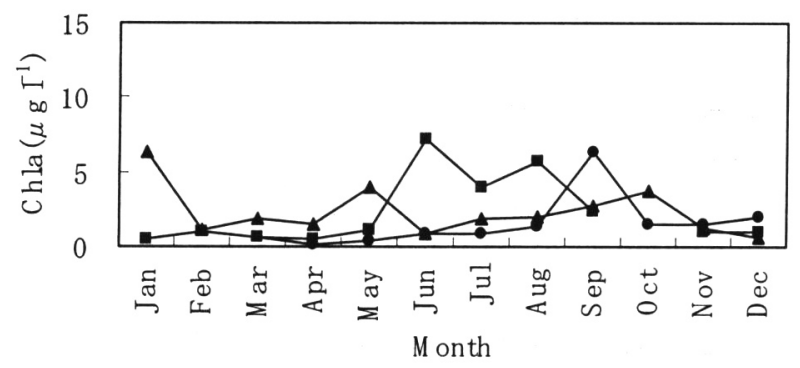

(b)

$\multimap 1996 \rightarrow-1997 \multimap 1998$

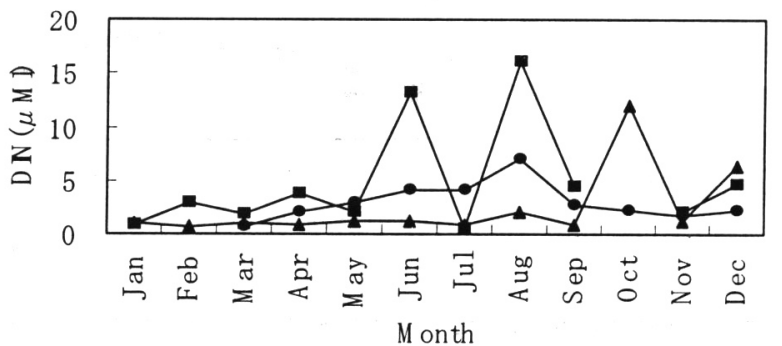

Figure 7. The seasonal variations of DIN (a) and chl.a (b) concentration in the outer area.

(a)
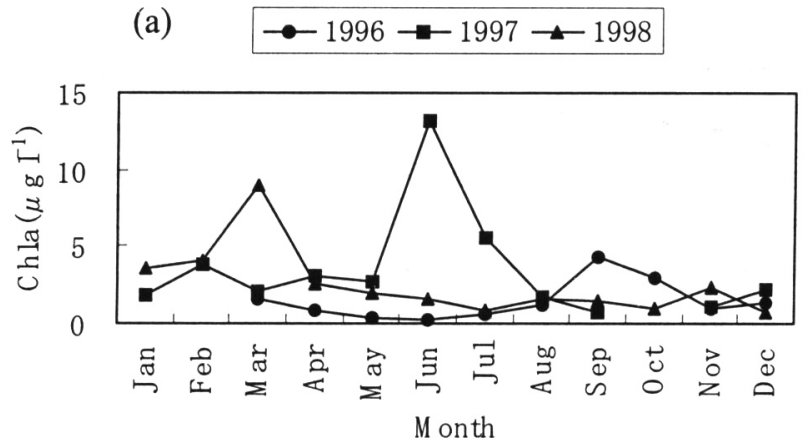

(b)

$$
\bullet 1996 \rightarrow-1997 \rightarrow 1998
$$

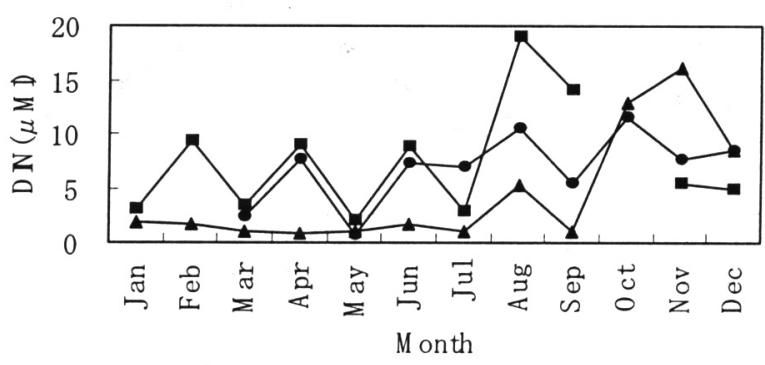

Figure 8. The seasonal variations of DIN (a) and chl.a (b) concentration in the lower layer. 
(a)

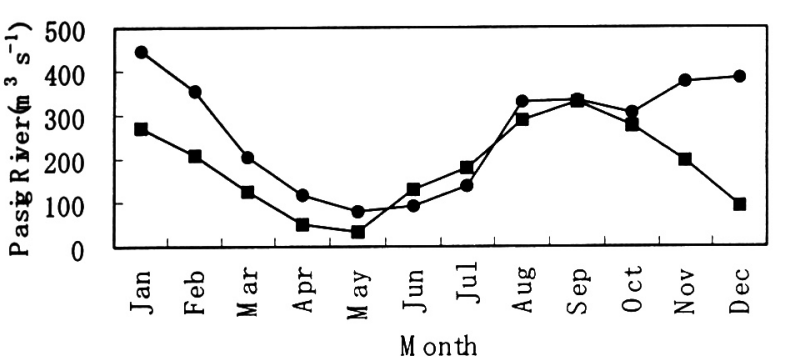

(b) $\multimap 1996 \rightarrow-1997$

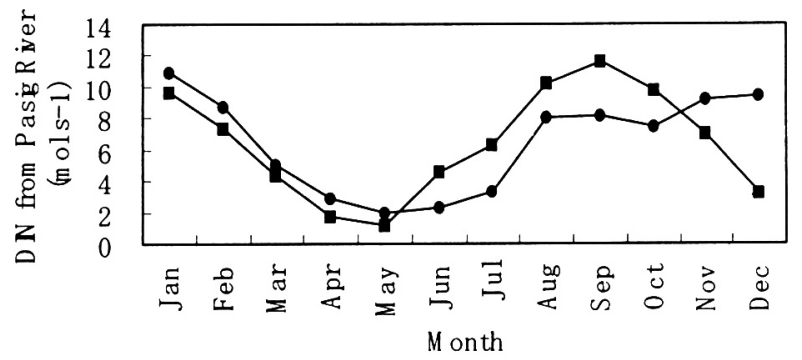

Figure 9. The seasonal variation of Pasig River discharge (a) and estimated DIN flux from land area.

Used parameters of the calculation are shown in Table 1 which are the same numbers used in Hayashi et al. (2006). The time step of the calculation is 1 hour. We obtained the quasi-steady state on the 10th days after the beginning of the calculation.

\section{RESULTS AND DISCUSSION}

Figure 10 shows the time series variation and Figure 11 shows the correlation between the calculation results and the observation data of chl.a (a) and DIN (b) concentrations. Calculated concentrations roughly reproduced the observed ones. But high chl.a concentrations in Aug. '96,
June '97, Jan. to March '98 and June '98 were not reproduced. Therefore we focus on two periods, March to May (dry season) and Aug. to Dec. (wet season), when the calculated chl.a concentrations agree well with the observed data on three years averaging as shown in Figure 12. River discharge shown in Figure 13 (a) is small and solar radiation shown in Figure 13 (b) is large in March to May. It is dry season, and chl.a concentrations are relatively low. River discharge is large and solar radiation is small in August to December. It is rainy season, and chl.a concentration is relatively high.

Photosynthesis is a function of DIN concentration, photon and water temperature as

Table 1. Parameters of the numerical ecosystem model.

\begin{tabular}{|c|c|c|}
\hline Parameters & Value & unit \\
\hline Maximum specific nutrients uptake rate by diatom & 2.0 & day $^{-1}$ \\
\hline Half saturation constant of nitrogen to diatom & 0.7 & $\mu \mathrm{M}$ \\
\hline Optimum water temperature & 31.0 & ${ }^{\circ} \mathrm{C}$ \\
\hline Optimum photon & 110 & $E m^{2} s^{-1}$ \\
\hline Ratio of extra cellular excretion of DON and DOP by photosynthesis & 0.135 & $\mathrm{~g} \mathrm{~m}^{-2} \mathrm{~s}^{-1}$ \\
\hline Mortality speed of phytoplankton at 0 deg-C & 14.5 & $\mathrm{~m}^{3} \mathrm{~g}^{\mathrm{P}-1}$ day $^{-1}$ \\
\hline Temperature dependency of mortality of phytoplankton & 0.069 & ${ }^{\circ} \mathrm{C}-1$ \\
\hline Threshold of phytoplankton density for grazing & 0.1 & $\mathrm{mg} \mathrm{chl.a^{-1 }}$ \\
\hline Ivlev constant & 0.47 & $\left(\mu \mathrm{g} \mathrm{chl.a} \cdot{ }^{-1}\right)^{-1}$ \\
\hline Grazing speed of phytoplankton by zooplankton at 0 deg-C & 0.2 & day $^{-1}$ \\
\hline Temperature dependency of grazing by zooplankton & 0.069 & ${ }^{\circ} \mathrm{C}^{-1}$ \\
\hline Constant for urine generation & 0.4 & \\
\hline Constant for fecal pellet generation & 0.3 & \\
\hline Mortality speed of zooplankton at 0 deg-C & 30.0 & $\mathrm{~m}^{3} \mathrm{gP}^{-1}$ day $^{-1}$ \\
\hline Temperature dependency of mortality of zooplankton & 0.069 & ${ }^{\circ} \mathrm{C}^{-1}$ \\
\hline Decomposition speed of detritus to Dissolved Inorganic Matter at 0 deg-C & 0.0100 & day $^{-1}$ \\
\hline Decomposition speed of detritus to Dissolved Organic Matter at 0 deg-C & 0.0075 & day $^{-1}$ \\
\hline Decomposition speed of DOM to DIM at 0 deg-C & 0.0150 & day $^{-1}$ \\
\hline Temperature dependency of decomposition of detritus to DIM & 0.069 & ${ }^{\circ} \mathrm{C}-1$ \\
\hline Temperature dependency of decomposition of detritus to DOM & 0.069 & ${ }^{\circ} \mathrm{C} \cdot 1$ \\
\hline Temperature dependency of decomposition of DOM to DIM & 0.069 & ${ }^{\circ} \mathrm{C}^{-1}$ \\
\hline
\end{tabular}



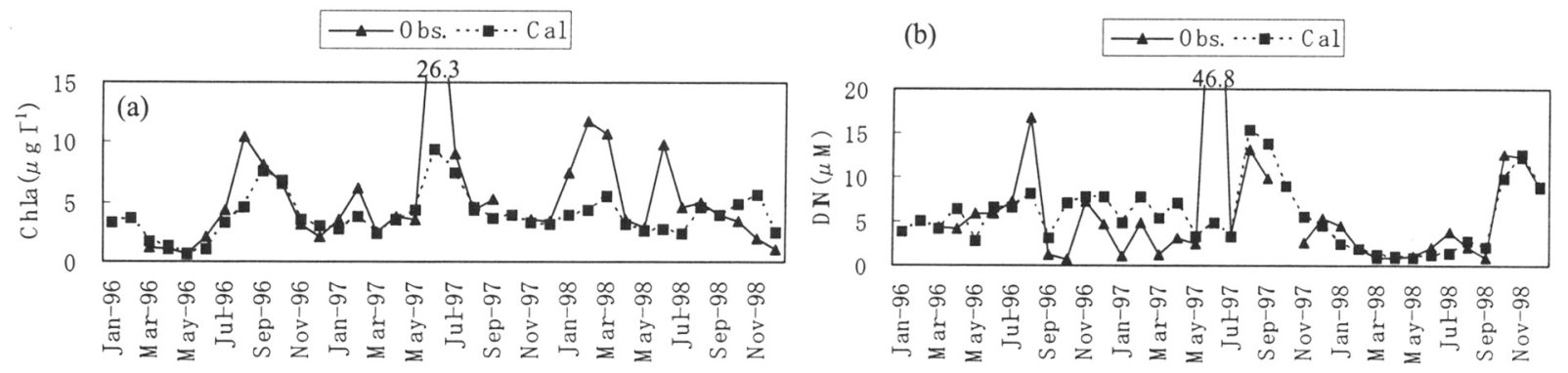

Figure 10. The temporal variations of the calculation results and the observation data of chl.a (a) and DIN (b) concentrations.


Figure 11. The correlations between the calculation results and the observation data of chl.a (a) and DIN (b) concentrations.

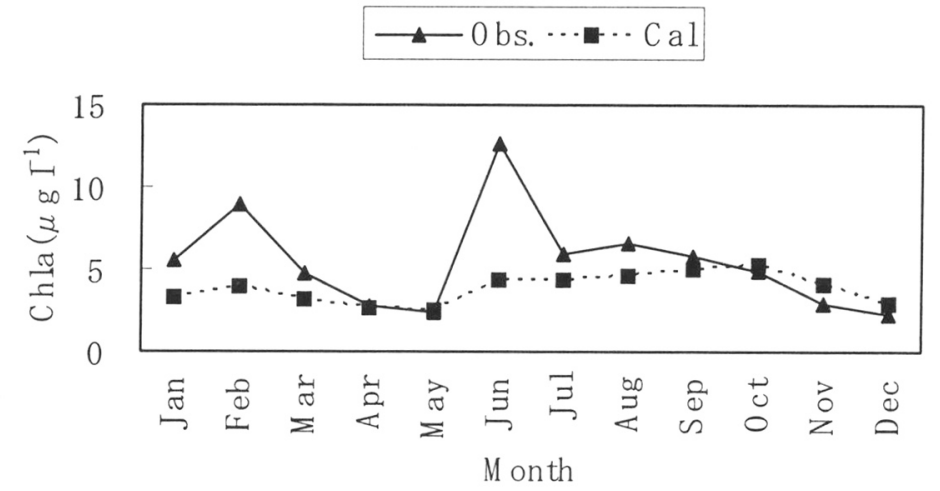

Figure 12. The seasonal variations of the calculation results and the observation data of chl.a concentration on 3 years averaging.


Figure 13. The seasonal variations of river discharge (a) and solar radiation (b) on 3 years averaging. 
shown in Equation 2. Figure 14 shows the seasonal variations of DIN concentration (a), photon in the water (b) and water temperature (c) on three years averaging. Calculated result of DIN concentration on three years averaging is also shown in Fig.14 (a). DIN concentrations correlates with Chl.a concentration. When chl.a concentration is relatively low in dry season, DIN concentration is also low. And when chl. a concentration is relatively high in rainy season, DIN concentration is also high. DIN concentration correlates with chl.a concentration. It is reasonable result and is one of the reasons of the seasonal variation of chl.a concentration. Fig. 15 shows the DIN fluxes from each source, Pasig River and the coastal zone, decomposition in the upper layer, the vertical transport and the vertical exchange. Main source of DIN in rainy season is the vertical transport from the lower layer due to strong estuarine circulation. And it seems that the source of DIN at the lower layer in the inner part of Manila Bay is decomposition in the lower layer. DIN concentration in the lower layer of the outer area of the bay is lower than that in the lower layer of the inner part of the bay as shown in Figure 3 (d).

Figure 16 shows the limiting force of primary production. Smaller number limits primary production stronger. Photon in the water during

(a)
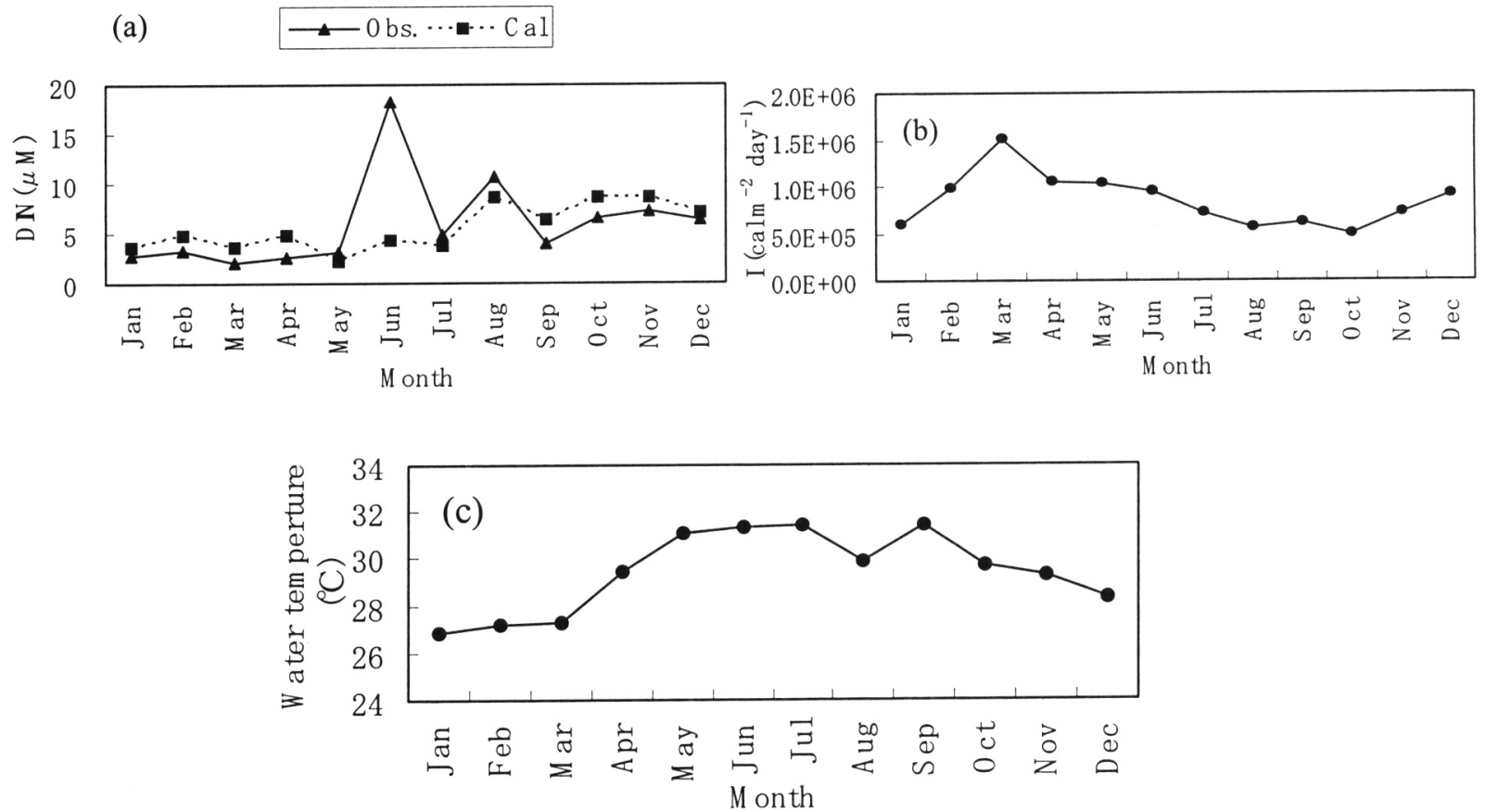

Figure 14. The seasonal variations of DIN concentration (a), photon in the water (b) and water temperature (c) on 3 years averaging.

\section{$\square$ Land $\mathbf{\square}$ Decom positin $\square \mathrm{W} \square \mathrm{Kv}$}

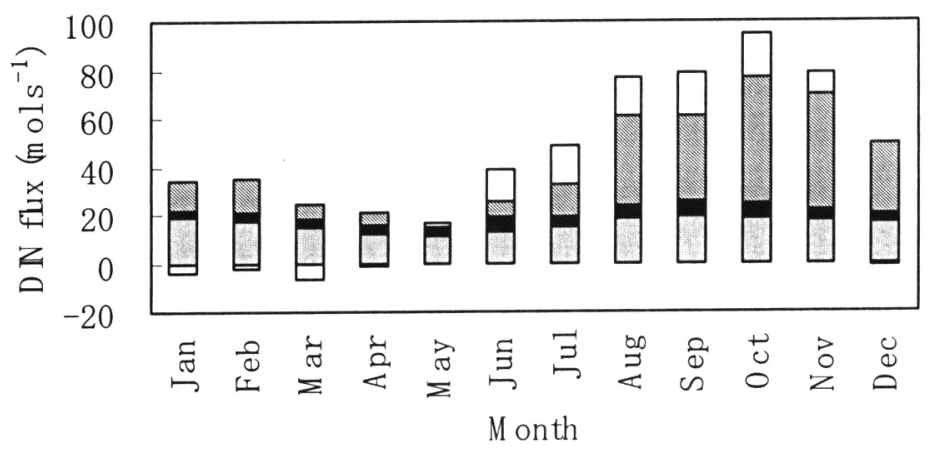

Figure 15. The seasonal variation of DIN fluxes from each source. 


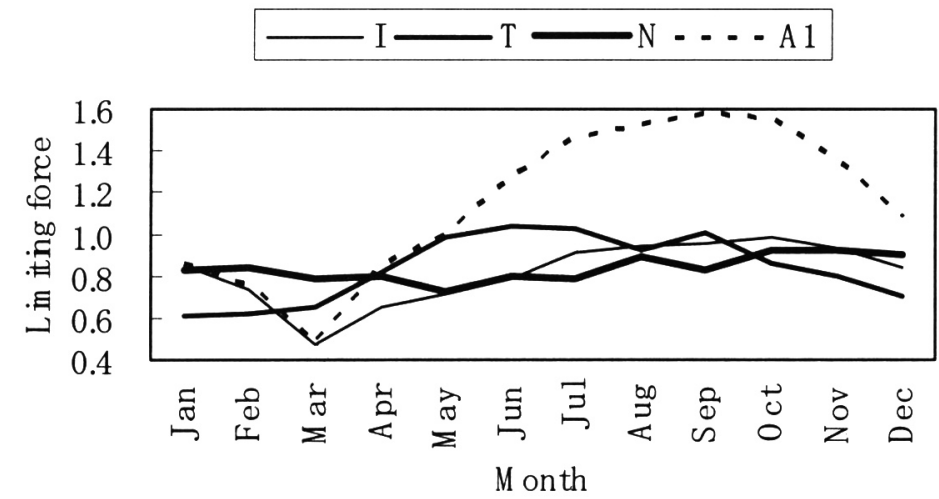

Figure 16. The seasonal variations of the limiting force of primary production. Smaller number limits primary production stronger.

(a)

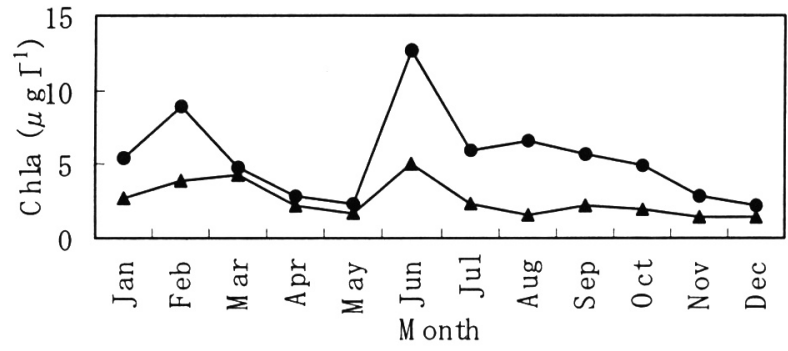

(b)



Figure 17. The seasonal variations of chl.a concentration in the upper and lower layers on 3 years averaging (a) and the vertical exchange of chl.a (b).

rainy season is relatively small, but is not strongest limiting factor to primary production because this small photon is optimum for photosynthesis. Strongest limiting factor is DIN in Aug. and Sep. and is water temperature in Nov. and Dec. On the other hand, the strongest limiting factor in dry season is photon in the water because of too strong solar radiation. In general, when solar radiation in the sea surface is too strong for phytoplankton, chl.a concentration maximum appears in the lower layer. In this case, we can find the same level of chla concentration in the lower layer compared with the upper layer as shown in Figure 17 (a). And the vertical exchange of chl.a is small as shown in Figure 17 (b). It means that phytoplankton in the lower layer grew up in the lower layer in dry season.

\section{CONCLUSION}

We calculated the monthly nitrogen cycling in the upper layer of the Manila Bay during Jan. 1996 to Dec. 1998, using the numerical ecosystem model. Chl.a and DIN concentrations are relatively low, river discharge is small, and solar radiation is strong from March to May in dry season. The main reason of low chl.a concentration is that solar radiation is too strong. On the other hand, as DIN concentration is relatively high and solar radiation is optimum, chl.a concentration is high from August to December in rainy season. Main source of DIN in rainy season is the vertical transport from the lower layer due to strong estuarine circulation. Such results correspond to Hayashi et al. (2006).

\section{REFERENCES}

Azanza, R.V., F. P. Siringan, M. L. San Diego-Mcglone, A. T. Yñiguez, N. H. Macalalad, P. B. Zamora, M. B. Agustin, and Matsuoka, K. 2004. Horizontal dinoflagellate cyst distribution, sediment characteristics and benthic flux in Manila Bay, Philippines. Phycological Research 52: 376-386.

Fe Farida A. Bajarias and Juan R. Relox, Jr. 1996. Hydrological and climatological parameter associated with the pyrodinium bloom in Manila 
Bay, Philippines: Harmful and Toxic Algal Blooms. In: Yasumoto, T., Oshima, Y. and Fukuyo Y. (eds.): Intergovernmental Oceanographic Commission of UNESCO: 49-52.

Fujiie, W., Yanagi, T. and Siringan, F. P. 2002. Tide, tidal current and sediment transport in Manila Bay. La mer 40: 137-145.

Hashimoto, T., Yamamoto, T., Tada, T., Matsuda, O., Nagase, T., Tada, Go A. and Nakaguchi, K. 1996. Seasonal investigations of water quality characteristics of the Seto Inland Sea. J. Fac. Appl. Biol. Sci. Hiroshima Univ. 35: 243-274 (in Japanese).
Hayashi, M. and Yanagi, T. 2002. Comparison of the lower trophic level ecosystem between Suo-Nada and Osaka Bay. Umino-knekyu 11: 591-611 (in Japanese).

Hayashi, M., Yanagi, T. and M. L. San Diego-Mcglone. 2006. Nitrogen cycling in Manila Bay during dry and rainy seasons. Coastal Marine Science 30(1): $49-53$.

Jacinto, G. S., M. L. San Diego-McGlone, Velasquez1, I. B. and Smith, S. V. 1998. N and P Budget of Manila Bay, Philippines. LOICS web site.

Yanagi, T. and Onitsuka, G.. 2000. Seasonal variation in lower trophic level ecosystem of Hakata Bay, Japan. J. Oceanogr 56: 233-243. 